\title{
Entropy of Stochastic Intuitionistic Fuzzy Sets
}

\author{
Adel Fatemi \\ Department of Mathematics, Islamic Azad University _ Sanandaj Branch, Kurdistan, Iran \\ fatemi@iausanandaj.ac.ir
}

\begin{abstract}
In this paper uncertainty measure of stochastic intuitionistic fuzzy sets due to hesitancy and randomness is proposed. It is extending of Deluca and Termini (1972) formula for IFSs.
\end{abstract}

\section{Keywords: Intuitionistic fuzzy sets, Stochastic, Entropy.}

\section{Introduction}

Entropy measures in the stochastic systems are the degree of uncertainty due to the randomness, while in the theory of fuzzy sets uncertainty is due to the vagueness and complexity of the system. Thus the fuzzy entropy can be considered as the degree of uncertainty due to the personal judgment. After three decades that Shannon [5] introduced the entropy of stochastic systems, De Luca and Termini [2] for the first time introduced the concept of fuzzy entropy. Their measure of fuzzy entropy was based on the fuzzy sets with finite reference set. This measure, which is based on the Shannon's measure of entropy. Kaufmann [3] defined the fuzzy entropy by the Euclidean or Hamming distance of the fuzzy set and the nearest crisp set. Yager [7] consider the relationship between $A$ and $A^{c}$ to be the essence of fuzziness. In spite of the apparent structural difference between Kaufmann and Yager's measures with De Luca entropy, they satisfy the four axioms introduced by De Luca and Termini. In 1992, Kosko [4] gave new version of Kaufmann's entropy. Concedering degree of hesitancy, Atanassov [1] defined intuitionistic fuzzy sets as the generalization of fuzzy sets. Szmidt. E., Kacprzyk [6] introduced the entropy for intuitionistic fuzzy sets and its axioms. In section 2 intuitionistic fuzzy sets and entropy are discussed. And finally in section 3 entropy of stochastic intuitionistic fuzzy sets is proposed.

\section{Intuitionistic fuzzy sets and entropy}

The concept of an intuitionistic fuzzy set (IFS), which is a generalization of the concept of a fuzzy set (FS), has been introduced by K. Atanassov.

\subsection{Preliminaries}

Definition 1. A traditional fuzzy set in $X$, given by

$A=\left\{\left(x, \mu_{A}(x)\right) \mid x \in X\right\}$

where $\mu_{A}: X \rightarrow[0,1]$ is the membership function of the fuzzy set $A$,

Definition 2. An intuitionistic fuzzy set $B$ is given by

$B=\left\{\left(x, \mu_{B}(x), v_{B}(x)\right) \mid x \in X\right\}$

where $\mu_{B}: X \rightarrow[0,1]$ and $\nu_{B}: X \rightarrow[0,1]$ are such that

$0 \leq \mu_{B}(x)+v_{B}(x) \leq 1$

and $\mu_{B}(x) ; \nu_{B}(x) \in[0,1]$ denote a degree of membership and a degree of non-membership of $x \in A$, respectively. 
For each intuitionistic fuzzy set in $X$ we have a "hesitation margin" $\pi_{B}(x)$, this is an intuitionistic fuzzy index of $x \in B$, it expresses a hesitation degree of whether $x$ belongs to $A$ or not. It is obvious that $0 \leq \pi_{B}(x) \leq 1$, for each $x \in X$.

$\pi_{B}(x)=1-\mu_{B}(x)-v_{B}(x)$

Therefore if we want to fully describe an intuitionistic fuzzy set, we must use any two functions from the triplet.

- Membership function

- Non-membership function

- Hesitation margin

2.2 Basic operations on IFSs

Atanassov defines a set of operations between two IFSs $A$ and $B$.

Definition 3. The union operator $U$ between $A$ and $B$ is given by $\mathrm{A} \cup \mathrm{B}=\left\{\left(\mathrm{x}, \max \left\{\mu_{\mathrm{A}}(\mathrm{x}), \mu_{\mathrm{B}}(\mathrm{x})\right\}, \min \left\{v_{\mathrm{A}}(\mathrm{x}), v_{\mathrm{B}}(\mathrm{x})\right)\right\} \mid \mathrm{x} \in \mathrm{X}\right\}$

Definition 4. The intersection operator $\cap$ between $A$ and $B$ is given by $\mathrm{A} \cap \mathrm{B}=\left\{\left(\mathrm{x}, \min \left\{\mu_{\mathrm{A}}(\mathrm{x}), \mu_{\mathrm{B}}(\mathrm{x})\right\}, \max \left\{v_{\mathrm{A}}(\mathrm{x}), v_{\mathrm{B}}(\mathrm{x})\right)\right\} \mid \mathrm{x} \in \mathrm{X}\right\}$

Definition 5. The complementary set Ac of $A$ is defined as

$$
\mathrm{A}^{\mathrm{c}}=\left\{\left(\mathrm{x}, v(\mathrm{x}), \mu_{\mathrm{A}}(\mathrm{x})\right) \mid \mathrm{x} \in \mathrm{X}\right\}
$$

\subsection{Intuitionistic fuzzy entropy}

De Luca and Termini proposed nonprobabilistic entropy for FSs and formulated the axiomatic requirements an entropy measure should comply with. Szmidt and Kacprzyk extended the axioms of De Luca and Termini, proposing the following definition for an entropy measure in the setting of IFSs theory.

Definition 7 (Szmidt and Kacprzyk [31]). An entropy on IFS(X) is a real-valued functional $\mathrm{E}: \operatorname{IFS}(\mathrm{X}) \rightarrow[0,1] 1]$, satisfying the following axiomatic requirements:

- $\mathrm{E}(\mathrm{A})=0$ iff $\mathrm{A}$ is a crisp set; that is $\mu_{\mathrm{A}}\left(\mathrm{x}_{\mathrm{i}}\right)=0$ or $\mu_{\mathrm{A}}\left(\mathrm{x}_{\mathrm{i}}\right)=1$ for all $\mathrm{x}_{\mathrm{i}} \in \mathrm{X}$

- $\mathrm{E}(\mathrm{A})=1$ iff $\mu_{\mathrm{A}}\left(\mathrm{x}_{\mathrm{i}}\right)=v_{\mathrm{A}}\left(\mathrm{x}_{\mathrm{i}}\right)$ for all $\mathrm{x}_{\mathrm{i}} \in \mathrm{X}$, that is $\mathrm{A}=\mathrm{A}^{\mathrm{c}}$

- $\mathrm{E}(\mathrm{A}) \leq \mathrm{E}(\mathrm{B})$ if $\mathrm{A}$ is sharper than $B$, i.e.

$$
\left\{\begin{array}{l}
\mu_{\mathrm{A}}(\mathrm{x}) \leq \mu_{\mathrm{B}}(\mathrm{x}) \text { and } v_{\mathrm{A}}(\mathrm{x}) \geq v_{\mathrm{B}}(\mathrm{x}), \text { for } \mu_{\mathrm{B}}(\mathrm{x}) \leq v_{\mathrm{B}}(\mathrm{x}) \\
\text { or } \\
\mu_{\mathrm{A}}(\mathrm{x}) \geq \mu_{\mathrm{B}}(\mathrm{x}) \text { and } v_{\mathrm{A}}(\mathrm{x}) \leq v_{\mathrm{B}}(\mathrm{x}), \text { for } \mu_{\mathrm{B}}(\mathrm{x}) \geq v_{\mathrm{B}}(\mathrm{x})
\end{array}\right.
$$

for all $\mathrm{x}_{\mathrm{i}} \in \mathrm{X}$.

$$
\text { - } \mathrm{E}(\mathrm{A})=\mathrm{E}\left(\mathrm{A}^{\mathrm{c}}\right)
$$

Moreover, an intuitionistic fuzzy entropy measure was defined as

$$
\mathrm{E}(\mathrm{A})=\frac{1}{n} \sum_{i=1}^{n} \frac{\max \operatorname{Count}\left(\mathrm{A}_{\mathrm{i}} \cap A_{i}^{c}\right)}{\max \operatorname{Count}\left(\mathrm{A}_{\mathrm{i}} \cup A_{i}^{c}\right)}
$$


where $\mathrm{n}=\operatorname{Cardinal}(\mathrm{X})$ and $\mathrm{A}_{\mathrm{i}}$ denotes the single-element IFS corresponding to the $i$-th element of the universe $X$. In other words, $A i$ is the $i$-th "component" of $A$. Moreover, max $\operatorname{Count}(A) \operatorname{denotes}$ the biggest cardinality of $A$ and is given by

$\max \operatorname{Count}(\mathrm{A})=\sum_{i=1}^{n}\left(\mu_{A}\left(x_{i}\right)+\pi_{A}\left(x_{i}\right)\right.$

\section{Entropy of Stochastic Intuitionistic Fuzzy Sets}

In this section first a simple form of intuitionistic fuzzy entropy measure is introduce, then it is extended to stochastic IFSs.

Definition 8. Simple intuitionistic fuzzy entropy for IFS A can be defined as $E_{u}(A)=\frac{1}{n} \sum_{i=1}^{n} e\left(x_{i}\right)$ where $e\left(x_{i}\right)=1-\sqrt{\left(\mu_{A}\left(x_{i}\right)-v\left(x_{i}\right)^{2}\right.}$

It is satisfying according to Szmidt and Kacprzyk axioms.

Definition 9. Stochastic intuitionistic fuzzy entropy for IFS A with a probability system $P=\left(p_{1}, p_{2}, \ldots, p_{n}\right)$ is defined as

$E_{S}(A)=\sum_{i=1}^{n} p_{i} e\left(x_{i}\right)$

Property 1. In case of the uniform probability system the stochastic intuitionistic fuzzy entropy is the same as the Simple intuitionistic fuzzy entropy.

Definition 10. Total stochastic intuitionistic fuzzy entropy for IFS A with a probability system $P=\left(p_{1}, p_{2}, \ldots, p_{n}\right)$ is defined as

$E_{T}(A)=E_{S}(A)+H(P)$

where $H(P)=-\sum_{i=}^{n} p_{i} \log p_{i}$ is the Shannon entropy.

Property 2. If probability system be a degenerate distribution system, $P=(0, \ldots, 1, \ldots, 0)$ ,then $E_{T}(A)=e\left(x_{i}\right)$.

\section{Conclusions}

This paper presented total entropy for stochastic intuitionistic fuzzy sets. This is a extending of other entropy measure introduced by De Luca and Termini, Szmidt and kacperzik.

\section{Bibliography}

Atanassov K. (1986), Intuitionistic fuzzy sets, Fuzzy Sets and Systems 20 (1) 87- 96.

De Luca A., Termini S. (1972), A definition of non-probabilitistic entropy in the setting of fuzzy theory. Inform. And Control, 20, 301-312.

Kaufmann A. (1975), Introduction to the theory of fuzzy subsets, Academic Press, New York.

Kosko B. (1992), Neural Networks and Fuzzy Systems, Prentice-Hall, Englewood Cliffs, NJ .

Shannon C.E. (1948), A mathematical theory of communication, Bell System Tech. J. 21, 379$423 ; 623-656$.

Szmidt E., Kacprzyk J. (2001)., Entropy for Intuitionistic Fuzzy Sets, Fuzzy Sets and Systems 118, 467-477.

Yager R.R. (1979), on measures of fuzziness and negation, Part I: membership in the unit interval, Internat. J. Gen. Systems 5. 